\title{
Framework for Optimizing Team Performance and Project NPV: Enhancing the Probability of Success by Team Alignment
}

\author{
Ruud Weijermars ${ }^{1}$ \\ ${ }^{1}$ Alboran Energy Strategy Consultants and Department of Geoscience and Engineering, Delft University of \\ Technology, Delft, Netherlands \\ Correspondence: Ruud Weijermars, Department of Geoscience and Engineering, Delft University of Technology, \\ Stevinweg 1, PO box 5048, 2600GA Delft, Netherlands. Tel: 31-15-2787-801. E-mail: \\ R.Weijermars@TUDelft.nl
}

Received: May 11, 2012 Accepted: August 10, 2012 Online Published: September 14, 2012

doi:10.5539/emr.v1n2p107 URL: http://dx.doi.org/10.5539/emr.v1n2p107

\begin{abstract}
This study addresses a gap in enterprise risk management related to project team performance. Poorly functioning teams may severely erode project net present value (NPV). The erosion of project NPV can be quantified in terms of probability of success (POS). In the oil business POS is based on success criteria for likelihood that exploration efforts for oil \& gas prospects will realize the EMV for those assets. Similarly, POS in team work and negotiations is based on success criteria for the likelihood that cooperation between team individuals will be able to deliver the maximum value for the project. Practical rules are formulated to support teams and team leaders in their efforts to optimize the alignment of team members in order to enhance the team's effectiveness. The probability of success (POS) is split into three fundamental factors of alignment: $\mathrm{P}_{\text {Culture }}, \mathrm{P}_{\text {Skills }}$ and $\mathrm{P}_{\text {Goals }}$. The dynamic effect of team learning on team alignment is graphed as the Cumulative POS. The cost of failure is graphed for a range of POS values, and visualizes the impact on the EMV of extra Team OPEX, each normalized by the project NPV. Applications are possible in all kinds of functional teams, including change management teams that need to build coalitions to effectuate lasting change. The interaction between members of engineering and other professional teams has been studied intensively, but the expression of team performance in numbers as quantified here is a new direction.
\end{abstract}

Keywords: NPV optimization, team performance, probability of success, probability of failure, oil and gas projects

\section{Introduction}

The combination of knowledge from what are traditionally poorly connected disciplines, petroleum exploration and social philosophy, provides a powerful tool for monitoring and improving team performance. Oil and gas companies have invested considerable effort into the development of uncertainty and risk analysis tools to better establish the anticipated net present value (NPV) of projects (Willigers \& Majou, 2010). Although cognitive bias in decisions for oil and gas projects has been highlighted as a human risk factor in recent studies (Welsh et al., 2008), the role of professionals in realizing full project NPV is crucial and merits further study. The optimization model outlined here rates the degree of team alignment and translates this into team effectiveness.

Engineering and other functional specialist teams that prove unable to collaborate effectively are a corporate risk factor that may jeopardize the project outcome and could cause shortfalls in the realization of the anticipated NPV. A portion of the organizational resources and energy will go lost if the team process is ineffective (Figure 1). For example, if a team manages to collaborate only with $75 \%$ effectiveness, some $25 \%$ of the projected project outcome may remain unrealized. If additionally a portfolio management team's efforts remain also suboptimum, capturing only $2 / 3$ of the potential value, then $50 \%$ of the company's value-adding potential remains unrealized (Figure 1). Portfolio optimization is a corporate strategy planning responsibility and the realization of the full portfolio value critically hinges on the quality of the portfolio team's work.

This study focuses on the performance of approved projects in the portfolio. Project execution is an operational responsibility for business units and project teams. The generic vision for team work is to add value for their organizations. The successful execution of the selected projects or portfolios must generate the anticipated cash flows. This means capital expenditure (CAPEX) on any of such projects must result in project completion on 
time, within budget and safely. The model outlined seeks to influence the success of project teams as an outcome of the degree of collaborative performance development over time.

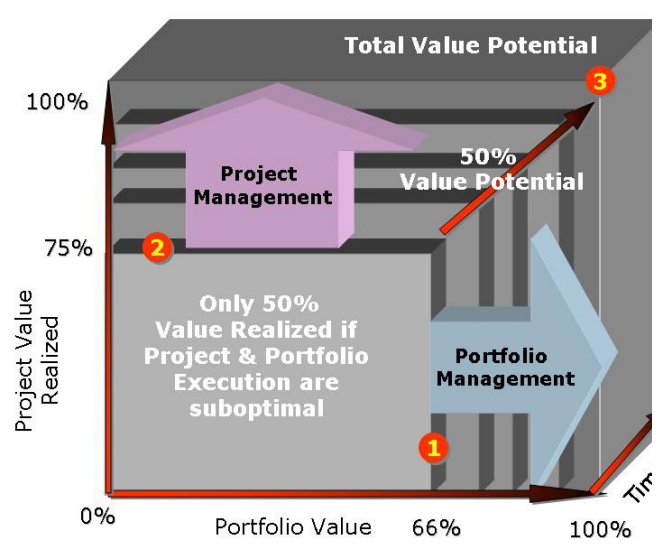

Figure 1. Optimization of the corporate strategy is critically dependent on operational project performance. Portfolio balancing techniques ensure that project impact is buffered against adverse project execution conditions, but the aim is that each investment project realizes the anticipated value

The monitoring of the progressive team alignment can quantify the likelihood that a project NPV will be realized as planned, or even optimized by the team when possible. The Expected Monetary Value (EMV) of a project in progress at times $T_{1}, T_{2}, T_{3}$, and $T_{N}$ will vary based on the effectiveness of team work (Figure 2). The projects originally anticipated NPV should be fully realized at $T_{N}$. Less effective teams will fail to optimize their alignment on the maximum performance and are likely to overrun project budgets and timelines for project completion. For project success, the EMV must match the original NPV, or even beat expectations. The model is designed to proactively monitor and manage changes in the degree of alignment (or degree of collaboration) between team members (Figure 2). Our approach supports industry in its ambition to manage talent and performance by numbers (Baker, 2008).

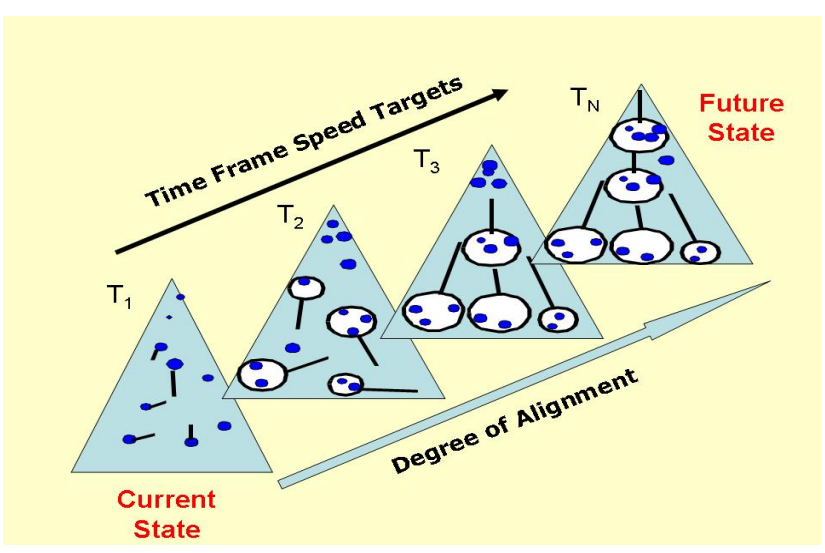

Figure 2. Alignment of team members needs to develop and improve over time (T1->TN) in order to optimize the collaboration between team members. Quantification of the effect of team alignment on project outcome is the focus of this study

The merits of our model are most critical when a team is newly assembled and faces tasks that are challenging and need new solutions rather than repetitive application of an established workflow. Examples of tasks in an established, rigid workflow are mostly blue collar projects. Problem solving teams are mostly engaged in white collar projects. 


\section{Previous Team Work Models}

Most organizations tend to be goal-oriented (here synonymous with task-oriented) and less people-oriented. Goal-oriented organizations run a risk of overlooking and disregarding the importance of improving team collaboration. Previous studies have already demonstrated that goal-oriented teams (star teams being the extreme, e.g., Fischer \& Boynton, 2005) may become surprisingly ineffective if they do not manage to fully align their talents into collaboration for the team task (Gratton \& Erickson, 2007). A people-oriented approach, as newly advocated in this study, is strongly recommended - if not a prerequisite for achieving an optimum project outcome with teams. Team members will work goal-oriented only as long as people issues are properly addressed. Team members that do not learn to understand each other cannot contribute super-effectively to the goals of their team.

Earlier studies focused on the importance of collaboration and concluded that members of large, complex teams can still collaborate effectively if the right conditions are in place (Gratton \& Erickson, 2007). Teams that are equipped with attributes to be effective in collaboration (large skills base, virtually connected, from diverse backgrounds and experienced professionals) are effective in their collaboration when team member alignment is optimum. Decision-making theories for predicting team outcomes commonly focus on the quantification of uncertainty in team outcomes, based upon the possible range of decisions of individual members (Axelrod, 1997; Ridley, 1998). Other models study the impact of team collaboration on the trade-off between the team's creativity to 'think-out-of-the-box' and convergence of ideas toward project completion with consensus, rather than divergence of ideas (Amabile, 1996, 1998; Thompson, 2003; Hoegl \& Parboteeah, 2007).

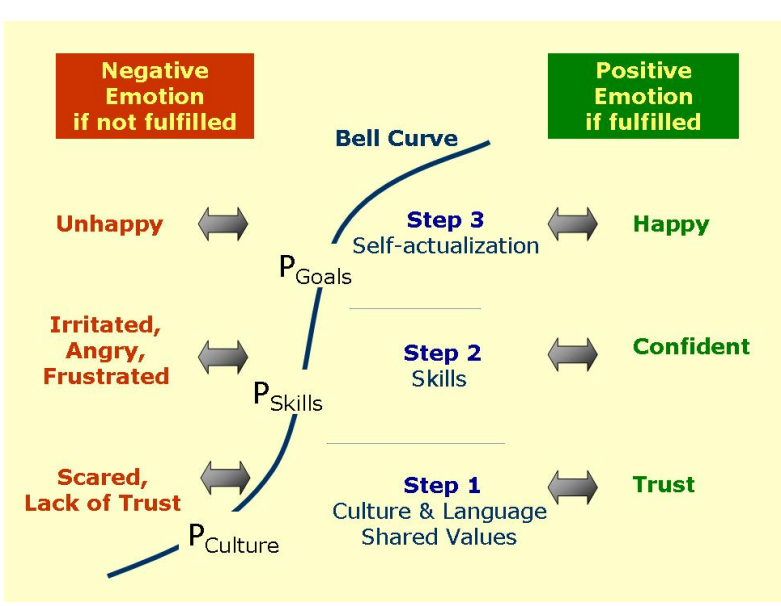

Figure 3. Cornelis generic concept of Feeling's Logic with probabilities (chance factors) indicated for each stability layer (modified from Cornelis, 1988)

We advance the progressive consolidation of alignment in teams based on the work of Cornelis (1988, 'Feelings Logic', written in Dutch and never translated into English; but briefly outlined in Weijermars, 2011). Cornelis provided a rational framework for the role of emotions in communication across socio-cultural systems. The great merit of the Cornelis 'Feelings Logic' lies in his recognition of the importance of emotional responses of team members to build social stability layers (Figure 3). Team members that understand and 'grasp' each other's cultural layer feel trusted, while they may still recognize culturally distinct habits of one another. Individuals in social entities seek to share a common language, adhere to cultural traditions, and display a tendency to respect similar customs and beliefs. The 'Feelings Logic' model of Cornelis (1988), partly covered by the better known concept of building emotional intelligence in teams (Goleman, 1997, 2000; Druskat \& Wolff, 2001), provides a comprehensive intellectual framework for the development of emotional intelligence in groups.

The Cornelis model of 'Feelings Logic' conceptualizes the embedding of emotions in so called 'social layers of stability' (Figure 3); three such layers are distinguished: 'Culture', 'Skills' and 'Self-actualization'. The social stability layers of Cornelis 'stack' on top of one another -optimizing the efficiency in the skills layer is contingent upon fulfilling the culture layer. Each layer needs conditional fulfilment for any action on the subsequent level to be effectively undertaken and may be applied to micro-scale (social entities such as teams), or to macro-scale (societal level). The theory of Cornelis (1988) has been previously expanded with a 
probabilistic approach which improves the chances of success in negotiations and subsequent collaboration between national (NOCs) and international oil companies (IOCs) (Weijermars et al., 2008). The theory has also been applied to international cooperation between gas companies (Weijermars \& De Jong, 2008).

\section{Cost of Failure in Optimizing Team Alignment}

The three major steps implied by the Cornelis model for the team alignment process are similar to the first three, essential steps in the well-known Drexler-Sibbet team performance model (Figure 4), which is used here as a reference frame for monitoring the probability of success (or failure) as teamwork.

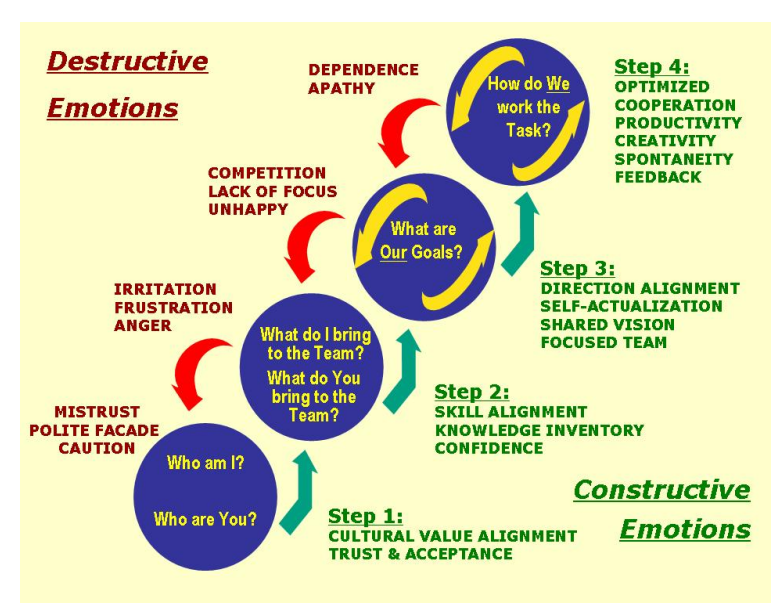

Figure 4. Effective team-functioning critically depends not only upon a spread of professional expertise: All team members must succeed in aligning their attitude towards collaboration. Only optimized alignment will enable positive knowledge sharing and team focus resulting in optimum outcomes (constructive, green track).

Poor team spirit leads to progressive corruption of cooperation and torpedoes knowledge sharing activities (destructive, red track). (Simplified from Drexler et al., 1988)

For effective team work, clearly non-alignment (destructive, red track in Figure 4) must be mitigated as it leads to inefficiencies and waste in the company's resources and energy. Assuming that the speed of correction for non-alignment in teams can be positively affected by the team members, the following rules must be observed:

1. The principal mechanism for optimizing the effectiveness of teams, once members are chosen, resides foremost in the degree of team alignment.

2. All things being equal, the team can optimize its performance with the members' skills and talent pool only by maximizing collaborative alignment (including using the full range of personal creativity for solving the challenges at hand).

3. The intrinsic possibility of success (POS) for the team can improve by a combination of individual learning to improve the skills of team members and by team learning to enhance the shared values and vision.

4. Cost of team work increases over time, but is offset by the quality and value of the expected project outcome, both of which can be maximized in team efforts where team members succeed in optimizing team alignment.

Goal-oriented organizations run a risk of overlooking and disregarding the importance of improving team collaboration, which requires a people-oriented approach based on a foundation of strong core values. When people and functional teams do not share common understanding and do not passionately support their corporate values and goals, this may result in that these organizational goals are not or ineffectively realized. The key to optimizing team performance lies locked inside the degree of alignment between team members. Progressive improvement of alignment in teams leads to better project outcomes.

Figure 5 provides a template for optimizing team alignment by capitalizing on insights from the Cornelis model on the social factors that control the alignment between team members (Figure 5). This template can be used to monitor the degree of team alignment as work is prepared, starts and progresses in teams. Progressive 
improvement of alignment in teams by starting people-oriented instead of goal-oriented, commonly leads to better outcomes.

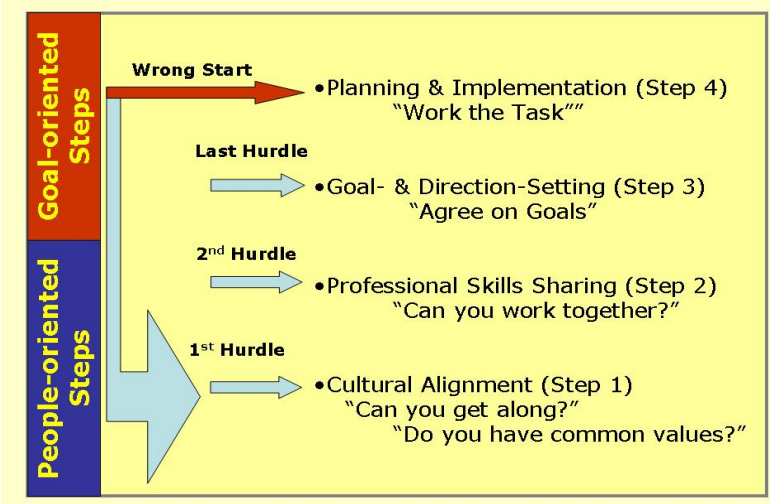

Figure 5. Most organizations tend to be goal-oriented and less people-oriented, but alignment of team members develops via shared core values and improves over time as the team focus grows

The assumption is that teams will be best able to deliver an expected project net present value (NPV) when the POS for the team is higher. A team's probability of success (POS) can thus be determined by the following product:

$$
\text { POS }=\mathrm{P}_{\text {Culture }} * \mathrm{P}_{\text {Skills } *} \mathrm{P}_{\text {Goals }}
$$

The Expected Monetary Value (EMV) that can be realized by a project team is given by (Weijermars et al., 2008; reformulating Johnston, 2003):

$$
\mathrm{EMV}=(\mathrm{POS} * \mathrm{NPV})-[(1-\mathrm{POS}) * \text { Extra Team Cost }]
$$

It is clear that a team with zero alignment, i.e. $\mathrm{POS}=\mathrm{P}_{\text {Culture }} * \mathrm{P}_{\text {Skills }} \mathrm{P}_{\text {Goals }}=0$, will not realize any positive EMV. The probability of failure (POF) grows as POS nears zero, i.e. POF $=1$-POS. The company is left with the cost of the teamwork, a negative result. In contrast, the optimum EMV is achieved when instant alignment is realized, i.e. $\mathrm{POS}=1$, so that EMV $=$ NPV. However, this is not a likely outcome as in most cases team performance needs time to improve.

The chance of failure can be $100 \%$, i.e. $P O F=1$, or zero if POS is $100 \%$ or 1 , and ranges between 1 and 0 for POS values between 0 and 1. It is clear that team members that learn to optimize their POS in a people-oriented team approach will thereby achieve the highest possible effectiveness for their team.

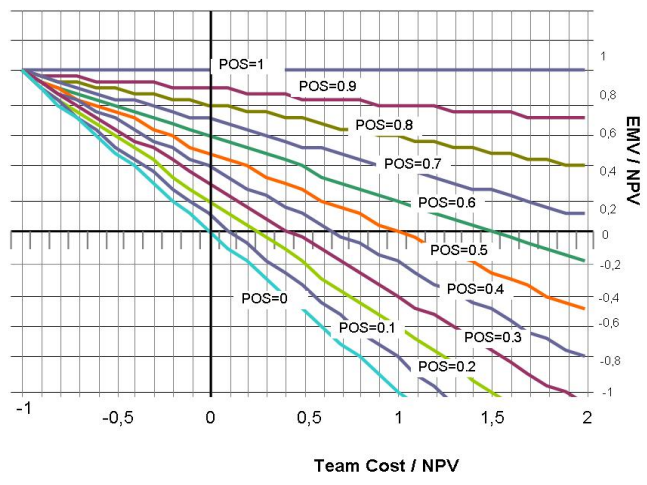

Figure 6. Expected team project outcome in monetary terms as EMV (normalized by the maximum NPV of the project) versus Team Cost (also normalized by the NPV) for POS values between 0 and 1

Figure 6 graphs the EMV, normalized by the NPV versus the Cost of Team Alignment, showing the impact of POS for the degree of team alignment $\left(\mathrm{POS}=\mathrm{P}_{\text {Culture }} * \mathrm{P}_{\text {Skills }} * \mathrm{P}_{\text {Goals }}\right)$. The probability of success in the case of moderate team alignment with POS $=0.5$ implies an EMV less than half the calculated NPV of the project. Only 
half the cost of team alignment is subtracted from the product of NPV*POS (see Eq. 2), because half the team's effort contributed to realize the EMV, but the other half did not.

While Equation 2 expresses the stochastically correct EMV, an alternative Equation subtracts the full value of the cost of team alignment, in analogy with the cost of exploration commonly used in mineral exploration programs (e.g., Lord et al., 2001; Olivier et al., 2008):

$$
\mathrm{EMV}^{*}=(\mathrm{POS} * \mathrm{NPV})-\text { Extra Team Cost }
$$

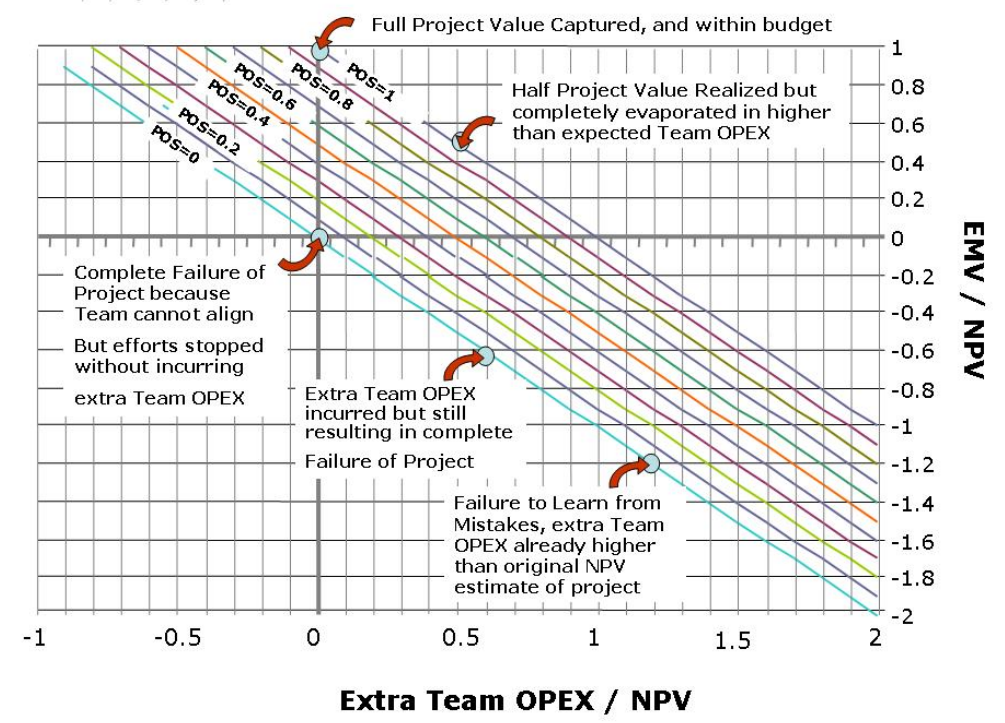

Figure 7. Expected project outcome in monetary terms as EMV* (normalized by the maximum NPV of the project) versus Team Cost (also normalized by the NPV) for POS values between 0 and 1

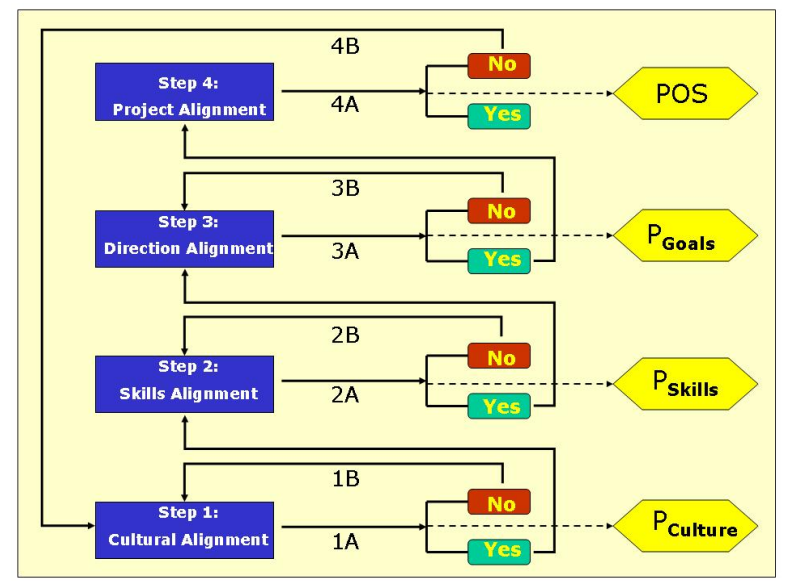

Figure 8. Flow chart for tracking team alignment and intrinsic POS scores for the team at a particular time TN, corresponding to arbitrary alignment stages shown in Figure 2

The relationship between EMV* and Team Cost, both normalized by the NPV, is graphed in Figure 8, according to Equation 3. Projects where the ratio Team Cost versus NPV is larger than 1 will yield negative EMV for all cases. Therefore, for most organizations, Equation 3 (and Figure 7) may provide a criterion better than Equation 2 (and Figure 6) to decide whether to terminate or kill a project. Alternatively, an argument against starting a project could be made when the anticipated cost for the required team alignment renders the ratio Team Cost versus NPV unattractive. For this consideration to be made, the effect of intrinsic POS augmentation as a result of team learning, were quantified in Figures 6 and 7. 


\section{Guidelines for Team Leaders for Monitoring Team Alignment}

The rules for optimizing the POS in team performance that is made up of the product $\mathrm{P}_{\text {Culture }} \mathrm{P}_{\text {Skills* }} \mathrm{P}_{\text {Goals }}$ (see Eq. 1) are outlined in this section. The flow chart of Figure 8 serves as a practical guideline for tracking team alignment and for tracking progress or regress in a team's intrinsic POS.

Assigning an experienced team leader who pays attention to people-skills as well as goal-setting issues is essential for the team's success. The regular assessment of the leadership styles of team leaders remains important; they must be familiar with the mechanisms of group dynamics and basic leadership models (Blake \& Mouton, 1964; Fiedler, 1967; Kirkpatrick \&Locke, 1991; Goleman, 1996; Collins, 2001).

The most basic social stability layer is the 'Culture' level, which refers to cultural 'embeddedness' of social groups, teams and companies alike, and the extent to which they have adopted a common language, norms and customs. Building team trust by addressing $\mathrm{P}_{\text {Culture }}$ requires skilful management from the team leader. Ideally, individuals in social entities (teams) share a common language, adhere to cultural traditions, and display similar customs and beliefs. One anecdote by George DeVries Klein (pers. comm. 7/11/2008) illustrates the point: "I recall one meeting involving a team of which I was a member, and the client's team. We all gave our presentations to the client team, but the geophysicist from the client-team was concerned about a difference between our geophysicist's use of 180-degree phase and their preferred 90-degree phase. While they slugged it out, the rest of us just sat there wondering why the two of them couldn't just work it out away from the team meeting. Neither team leader stepped in to make that happen. Although eventually resolved, it left hard feelings that weren't needed and made for a difficult working relationship between both groups. During a break, I met with my counterpart to smooth things over and that at least led to some progress."

Factors that are seen to improve interaction between members of engineering teams and result in positive collaboration are (Gratton \& Erickson, 2007): role models of collaboration by the senior executives, investment in facilities that foster open communication and collaboration, mentoring and coaching for cooperation in networks across corporate boundaries, training to improve people skills (teamwork, emotional intelligence, conflict resolution, networking and holding difficult conversations), building a sense of community (i.e. core values an social bonding), assigning team leaders that are both people-oriented and task-oriented, and picking teams that have a core of people that hold shared values, and then ensuring role clarity and task latitude.

To help team leaders assess the POS of team performance, a workflow template is provided (Figure 8). The three principal steps are outlined below:

Step 1: As a first step, a team leader should assess the team's cultural alignment (Figure 8, Step 1). The score for POS of a team critically depends on the incremental success in overcoming the individual resistances to team alignment. Team alignment at the cultural level is a first hurdle for optimizing the POS. The team score for $\mathrm{P}_{\text {Culture will be higher as individual scores }} \mathrm{P}_{\mathrm{j}}$ Culture of team members increase, according to:

$$
\mathrm{P}_{\text {Culture }}=\left(\sum_{\mathrm{j}=1} ; \quad \mathrm{P}_{\mathrm{j} \text { Culture } /}\right) / \mathrm{N}
$$

Table 1. Chance Factors assigned to individual team member compliance with the criteria set of Table 2

\begin{tabular}{lc}
\hline Criteria Compliance & Chance Factors \\
\hline Outstanding & $0.9-1$ \\
Excellent & $0.8-0.9$ \\
Good & $0.7-0.8$ \\
Satisfactory & $0.5-0.7$ \\
Insufficient & $0.3-0.5$ \\
Weak & $0.1-0.3$ \\
Poor & $0-0.1$ \\
\hline
\end{tabular}

With $\mathrm{N}$ the number of team members. The team's current $\mathrm{P}_{\text {Culture }}$ at time $\mathrm{T}_{\mathrm{x}}$ can be succinctly scored using two criteria: (A) the degree of integration of individual team members with the corporate culture and communication style, and (B) intercultural experience of team members. The scale proposed for scoring the $\mathrm{P}_{\text {Culture }}$ criteria is shown in Table 1. The foundation for achieving further cultural alignment in the team $\left(\mathrm{P}_{\text {Culture }}\right)$ lies in ensuring that: 
- Core values are well-integrated into the company's corporate culture and are shared by all team members.

- Teams can be formed and function without major resistances between team members. Team members have an excellent social cohesion.

- Teams can be formed from people most likely to enter into a knowledgeable dialogue about the task at hand.

The mechanisms for better alignment of $\mathrm{P}_{\text {Culture }}$ in multicultural teams can be abstracted from the detail studies of the impact of cultures on teams and negotiations (Trompenaars \& Hampden-Turner, 1997; Hofstede \& Hofstede, 2004). Further anecdotes of failed projects in the petroleum industry due to neglecting of $\mathrm{P}_{\text {Culture }}$ have been recounted by Klein (1999). In case any of the prerequisites for high team score of $\mathrm{P}_{\text {Culture }}$ are not fulfilled, it is important to not proceed until these prerequisites are in place by intervention and remediation of the situation (Figure 8, track 1B).

Step 2: The second step for the team is to work on raising their score for alignment at the skills level or $\mathrm{P}_{\text {Skills. }}$ The 'Skills' level refers to the specific set of skills the people in a certain social group or team require for successful functioning. The emotional responses related to the skill layer are 'confidence' for those team members who have the appropriate skills - and 'frustration' for those that do not. Personal creativity and variety in innate cognitive styles can be inventoried using Myers-Briggs type inventories and diversity spread can be established using the models of Belbin (1993), Herrmann (1996) and Lumsdaine et al. (1999). These are all useful analytical tools that help to improve insight in the personal traits that affect team chemistry and creative skills. Skills include the recognition of - and adherence to - the economic, legal and political systems. A team leader (project manager) must ensure that team members have a professional attitude about their individual strengths and weaknesses. The success of a project is based upon their mutual experience, skills, practitioner record and education level $\left(\mathrm{P}_{\text {Skills }}\right)$ :

- The team will benefit if the team leader and team members jointly prepare a skill inventory needed for the task at hand and compare this with the range of skills covered by team members.

- Team members have a professional attitude about individual strengths and weaknesses, based upon an inventory of individual experience (practitioner record \& education level).

- Team members understand the skills needed for the team task at hand, and their preparedness is high to share knowledge, learn and bridge skills gaps. Skill gaps can be plugged by attracting new team members or by rapid continuing education of current members.

- Team members are willing to share quality assurance tools and common standards.

- Skills needed by the team but not (yet) mastered by any member can be complemented by attracting new team members, by inviting experts for advice, or by rapid continuing education of current members.

- In fact, a team's effort for an inventory of skills at hand and cross-checking with skills needed itself is an exercise that may lead to high team scores for $\mathrm{P}_{\text {Skills. }}$. There must be a preparedness to share knowledge, to learn and to work actively to bridge skills gaps. Team members should also be willing to share quality assurance tools and common industry standards.

The team score for $\mathrm{P}_{\text {Skills }}$ increases as individual scores $\mathrm{P}_{\mathrm{j} \text { Skills }}$ of team members align, according to:

$$
\mathrm{P}_{\text {Skills }}=\left(\sum_{\mathrm{j}=1} ; \quad \mathrm{P}_{\mathrm{j} \text { Skills }}\right) / \mathrm{N}
$$

The team should inventory its skills required for the project (Figure. 8, track 2A) and assess whether the skills and experience base of team members are adequate. The team's current $\mathrm{P}_{\text {Skills }}$ at time $\mathrm{T}_{\mathrm{x}}$ can be succinctly scored using two criteria: (C) Skills adequacy, and (D) years of experience in applying the skills. The scale proposed for scoring the $\mathrm{P}_{\text {Skills }}$ criteria is as shown in Table 1.

Step 3: The third step is to work in teams on raising the score for alignment at the goals level or $\mathrm{P}_{\text {Goals. }}$ In the upper social stability layer, 'self-actualization' refers to people's ability to formulate and realise their goals and ambitions within a social entity. It is highly implausible for a member of any society, organization, or team to realize their goals and ambitions (self-actualization) if not supported by a social culture (common understanding of core values), and effective sharing of skills and knowledge. A team then may succeed in accomplishing favourable alignment in the self-fulfilment layer. Team member are happy when this is achieved, and sad and unsuccessful if this is not the case. Teams are commonly formed to assume responsibility for inventorying or assessing particular types of problems and then proceed to suggest solutions. However, the method of solution 
focus and vision for solving the challenge is entirely the team's responsibility. Great leaders know how to inspire and empower teams to formulate solutions (Collins, 2001):"First get on the bus - then we decide where we go."

Effective goal- and direction-setting in the team $\left(\mathrm{P}_{\text {Goals }}\right)$, becomes possible only if the vision for the project's objectives is shared by all team members:

- A vision for the project's objectives shared by all team members leads to effective teamwork.

- Specific goals are agreed, clear and supported by all team members.

- A real sense of mission toward objectives and goals is shared by the team.

The team score for $\mathrm{P}_{\text {Goals }}$ increases as individual scores $\mathrm{P}_{\mathrm{j} \text { Goals }}$ of team members align, according to:

$$
\mathrm{P}_{\text {Goals }}=\left(\sum_{\mathrm{j}=1} ; \mathrm{P}_{\mathrm{j} \text { Goals }}\right) / \mathrm{N}
$$

The team should discuss the goals and mission objectives for the project (Figure. 8, track 3A) and make sure there is agreement on a shared vision and goals. The team's current $P_{G o a l s}$ at time $T_{x}$ can be succinctly scored using two criteria: (E) Vision for solutions for the project are adopted and supported, and (F) the goals are understood by all team members. The scale proposed for scoring the $\mathrm{P}_{\text {Goals }}$ criteria is as shown in Table 1 .

Table 2. Team alignment scorecard

\begin{tabular}{|c|c|c|c|c|c|c|c|}
\hline $\begin{array}{l}\text { Stability } \\
\text { Layer }\end{array}$ & \multicolumn{2}{|c|}{ Step 1: $\mathrm{P}_{\text {Culture }}$} & \multicolumn{2}{|c|}{ Step 2: $P_{\text {Skills }}$} & \multicolumn{2}{|c|}{ Step 3: $\mathrm{P}_{\text {Goals }}$} & $\begin{array}{l}\text { Individual } \\
\text { POS } \\
\text { scores }\end{array}$ \\
\hline Criteria & $\begin{array}{c}\text { (A) } \\
\text { Corporate } \\
\text { Culture \& } \\
\text { Communication } \\
\text { Style Fits }\end{array}$ & $\begin{array}{c}\text { (B) } \\
\text { Level of } \\
\text { Multicultural } \\
\text { Experience }\end{array}$ & $\begin{array}{c}(\mathrm{C}) \\
\text { Skills } \\
\text { for } \\
\text { Task } \\
\text { Set }\end{array}$ & $\begin{array}{c}\text { (D) } \\
\text { Skills } \\
\text { Experience } \\
\text { Level }\end{array}$ & $\begin{array}{c}(\mathrm{E}) \\
\text { Vision } \\
\text { Adopted } \\
\& \\
\text { Supported } \\
\text { with } \\
\text { Passion }\end{array}$ & $\begin{array}{c}(\mathrm{F}) \\
\text { Project } \\
\text { Goals } \\
\text { Understood } \\
\& \\
\text { Supported } \\
\text { with } \\
\text { Passion }\end{array}$ & \\
\hline $\begin{array}{l}\text { Person } 1 \\
\text { Person } 2 \\
\text { Person } 3\end{array}$ & & & & & & & $\begin{array}{l}\text { Score } 1 \\
\text { Score } 2 \\
\text { Score } 3\end{array}$ \\
\hline $\begin{array}{l}\text { Person N } \\
\text { Team } \\
\text { Total } \\
\text { Averages }\end{array}$ & $\begin{array}{l}\mathrm{P}_{\text {Culturer(A) }}+\text { Culture(B) } \\
\left(\sum_{\mathrm{j}=1} ; \quad \mathrm{P}_{\mathrm{j}} \text { Culture (A) }\right.\end{array}$ & $($ Culture (B) $) / 2 \mathrm{~N}$ & $\begin{array}{l}\mathrm{P}_{\text {Skills(C) }} \\
\left(\sum_{\mathrm{j}=1} ;\right. \\
(\mathrm{D}) /)^{\prime} / 2 \mathrm{~N}\end{array}$ & $\begin{array}{l}= \\
\text { ills (C) }+ \text { (Skills }\end{array}$ & $\begin{array}{l}P_{\text {Goals(F) }(\mathrm{F})+\mathrm{G}} \\
\left(\sum_{\mathrm{j}=1} ; \mathrm{P}_{\mathrm{j}}\right. \\
(\text { Goals (F) }) / 2 \mathrm{I}\end{array}$ & $\begin{array}{l}\mathrm{s}(\mathrm{F})= \\
\text { als }(\mathrm{E})+\end{array}$ & $\begin{array}{l}\text { Score N } \\
\text { Team } \\
\text { POS } \\
\text { Average } \\
\text { (Eq. 1) }\end{array}$ \\
\hline
\end{tabular}

Table 2 provides a Team Alignment Scorecard which can be used by team leaders and evaluated episodically with their team members. The scorecard outcome provides a single number which is a measure for the probability of success (POS) of the team. The POS for the team's efforts grows with their degree of alignment at each social stability layer. Periodic appraisal of the team POS using the criteria of Table 2 can monitor team progress. The POS for a team should increase as obstacles to collaboration are gradually removed as the team's collaboration efforts intensify. For team alignment, the sense that everyone succeeds or fails together remains important.

After completion of Steps 1 to 3, the team's intrinsic POS can be calculated from (Eq. 1) as

POS $=P_{\text {Culture }} * P_{\text {Skills* }} P_{\text {Goals. }}$ The fourth step (Figure 8 , Step 4) consists of completion of the project in sustained alignment of the team members on the project work. Even if the project goes well, it is still worthwhile to assess POS at regular intervals (Figure 8, track 4A). If the project scope needs revision, team members should not hesitate to revisit the three fundamental steps for team alignment (Figure 8, track 4B). Teams must be articulate and define their objectives and scope of work. If objectives remain diffuse, the outcome will be diffuse

Non-alignment in teams may also occur due to organizational problems (Kotter, 1978); this may occur when: 
- Formal directions for strategic change are not supported by social structures and core values in the company. Consequently, teams will lack a sense of direction and their poor core value adoption handicaps the development of team focus.

- The company's elaborate procedures and well-structured hierarchy of the past do not fit the current market dynamics. Consequently, alignment of members in teams suffers from mis-alignment between the organizational focus and best-practice in the external business environment.

- Fast change in external environment cannot be coped with competitively by the organization's current technology, current people and current assets. Consequently, team members lack skills and tools to achieve full alignment in team work.

- Goals and strategy of the company's dominant coalition are based on wrong assumptions about external environment. Consequently, team work in such strategically disconnected organizations is frustrated by inadequate leadership.

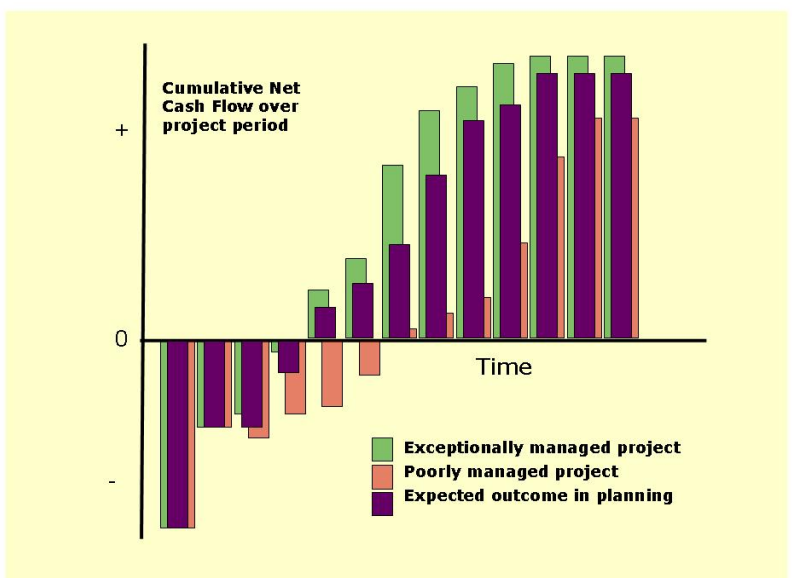

Figure 9. Anticipated NPV (= the cumulative cash flow over the life-cycle of the project) may be as planned in well managed projects. Poorly managed projects result in lost cash flow. Exceptionally well managed projects may beat the originally planned cash flow

In case any, if the prerequisites for high team score $\mathrm{P}_{\text {Goals }}$ are not fulfilled, it is important to not proceed until these prerequisites are in place by intervention and remediation of the situation.

As a project moves forward, it is crucial to determine how objectives change with new findings and interim project milestones. The EMV of the project can be episodically quantified based on the POS assessment using Equation (3). Figure 9 shows the hypothetical outcomes for an asset investment development project. Cash flow may be higher than expected if the EMV beats the NPV. Cash flow falls short of the scheduled cash flow when $\mathrm{EMV}<\mathrm{NPV}$. Cash flows are as planned when $\mathrm{EMV}=\mathrm{NPV}$.

\section{Examples of Team Alignment Challenges}

Some examples may serve to demonstrate the application of the previous theory as a team alignment monitoring-tool. A range of survival games is widely used to examine team performance when strategic choices have to be developed in teams. Commonly, the life of the team members - or a high reward - is at stake in such games. Consider the Moon Survival Game (a classic game described on numerous websites), where the goal is getting back to the designated rendez-vous point with the mothership after crash landing with an orbiter. Similarly, in the Alaskan Gold Mine Game, team members need a strategy plan to get back to the City from a remote location with limited supplies to lay claim to the prospect before expiration of the mine's exploration license.

Such crisis management simulation games impose a situation where teams are supposed to instantly align on $\mathrm{P}_{\text {Goals, }}$, whereas $\mathrm{P}_{\text {Culture }}$ and $\mathrm{P}_{\text {Skills }}$ need to be sorted out quickly in the team in order to reach the designated location with limited supplies and within a limited time period. Playing such survival games in teams of professionals provides a wealth of empirical evidence for potential obstacles to achieving perfect or $100 \%$ alignment for $\mathrm{P}_{\mathrm{Goals}}$, i.e. $\mathrm{P}_{\mathrm{Goals}}=1$. For example, a number of professionals may have difficulty identifying with the authenticity of the game simulation and simply disengage. The impact on the team score for $\mathrm{P}_{\text {Goals }}$ in a group 
of ten members by one member disengaging with $\mathrm{P}_{\mathrm{j} \text { Goals }}=0.1$ is that $\mathrm{P}_{\text {Goals }}$ dwindles to 0.91 for the team (see Eq. 5). Every next member that disengages lowers the $\mathrm{P}_{\text {Goals }}$ for the team by nearly $10 \%$. If half the team members disengage from the purpose of the game, $\mathrm{P}_{\text {Goals }}$ reduces to 0.55 or $55 \%$ of optimum team alignment for goals.

Assuming that the remaining team members succeed in reaching $100 \%$ alignment for both $\mathrm{P}_{\text {Culture }}$ and $\mathrm{P}_{\text {Skillss }}$, then the probability of success POS $=\mathrm{P}_{\text {Culture } *} \mathrm{P}_{\text {Skills* }} \mathrm{P}_{\text {Goals, }}$, gives at best a POS $=0.55$, according to Equation 1 . If lifes are at stake, such as in the Moon Landing Game, a POS of 55\% means $45 \%$ of the team members do not survive because they do not reach the agreed pick-up location, which is the goal of the exercise.

The team performance in survival games outlined above is exemplary for the performance of teams that need to realize change in companies that are under severe competitive pressure or threat from the external environment. Change management teams commonly need to become convinced that there is a burning platform situation (Conner, 1992). The fable by Kotter and Rathgeber (2006) replaces the burning platform by a melting iceberg, and provides a powerful metaphor for companies under threat. The essence of change management is that without rapid re-alignment by the company and a sense of urgency to adapt to changes in its external business environment (Kotter, 1978), the company's future may be at serious risk. In other words, achieving a high degree of alignment for the agreed objectives (i.e. $\mathrm{P}_{\text {Goals }}>0.8$ ) is a prerequisite for successful change management. Research by PROSCI (2007) has revealed that the impact of effective change management is excellent if some $88 \%$ of the key players meet the agreed change objectives. Further, change management effects are good if some $75 \%$ meet the objectives, fair if only $45 \%$ meet the objectives and right-out poor if a mere $17 \%$ meet the change management objectives.

\section{Cumulative POS and Effect of Team Learning}

Team alignment on certain issues can accelerate if the team learns and the intrinsic POS grows over time with each meeting. In reality, a team's intrinsic POS will rarely remain constant over time as teams learn and the degree of alignment commonly grows over time. A people-oriented approach, provides learning opportunities for team members to optimize their POS.

Explorationists in the oil industry know that drilling more wells with equal POS provides a cumulative POS (Rhoads, 2005). In analogy, the number of meetings of a team, when effective, will increase the cumulative POS. The Cumulative probability of success expresses the cumulative changes in team alignment over time (e.g. using equations from Rhoads, 2005):

$$
\text { Cumulative POS }=1-\left[\left(1-\mathrm{POS}_{1}\right) *\left(1-\mathrm{POS}_{2}\right) *\left(1-\mathrm{POS}_{3}\right) * \ldots\left(1-\mathrm{POS}_{\mathrm{N}}\right)\right]
$$

where $\mathrm{POS}_{\mathrm{N}}$ is the probability of success at the N-th attempt. Alternatively, the team's intrinsic POS does not change over time but the Cumulative POS does grow, as follows (Johnston, 2003, Johnston and Johnston, 2002; and Kjemperud, 2004):

$$
\text { Cumulative } \mathrm{POS}=1-(1-\mathrm{POS})^{\mathrm{N}}
$$

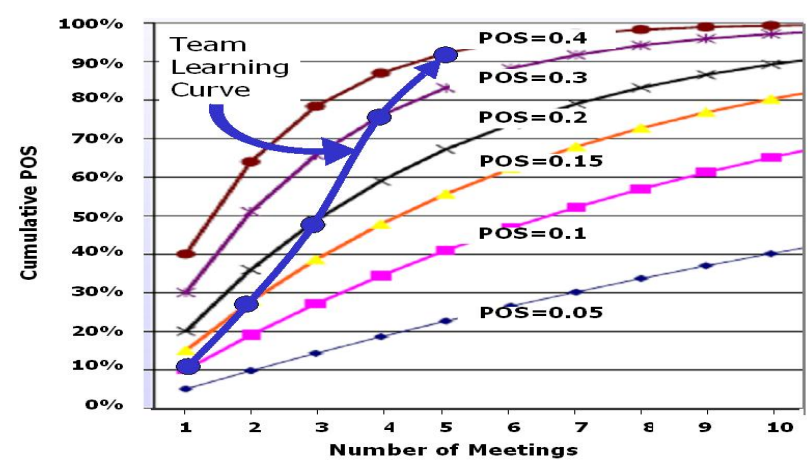

Figure 10. Cumulative POS for alignment on a topic in team work increases as the number of meetings held increases, even if the POS for the team remains constant. The blue line shows a team where the team's intrinsic POS grows from 0.1 , to 0.15 , to 0.2 , to 0.3 , to 0.4 over the period of five team meetings or attempts to tackle an issue. Their Cumulative POS grows even faster from 0.1 , to 0.28 , to 0.49 , to 0.75 , to 0.91

Figure 10 graphs the Cumulative POS (acc. to Eq. 7b) versus the number of meetings for groups that are locked in specific intrinsic POS scores for the team. For example, if the intrinsic POS for the team is 0.4 , this means that team members will align for only $40 \%$ of the decisions or actions to be taken for achieving an optimum project 
outcome. Teams that score a low intrinsic POS (as defined in Eq. 1) of say 0.1, and that do not learn to improve alignment at any subsequent meeting, will have a chance to score an EMV that is only $40 \%$ of NPV, even after 5 meetings, based upon the cumulative POS for alignment (Figure 10, Eq. 7b). The NPV lost by suboptimum team alignment has been quantified and graphed in Figures 6 and 7, respectively. In both calculations, the decline in EMV and loss of NPV due to suboptimum team work justifies active investment to improve team alignment in order to mitigate the NPV loss.

Figure 10 includes the Cumulative POS path for a team that learns, so that there is an additional effect on the Cumulative POS: higher intrinsic POS for the team at each meeting adds onto the Cumulative POS effect on team alignment at each new meeting. The enhanced effect of the Cumulative POS for learning teams benefits the growth of EMV* (see Eq. 3). After 5 meetings, the Cumulative POS for alignment over an issue may have risen to $40 \%$ even when the intrinsic POS for the team remains unchanged at $10 \%$. In the case of effective team learning, that is the team's intrinsic POS as assessed in subsequent meetings begins to exceed the team's initial POS, than the Cumulative POS (Eq. $7 \mathrm{~b}$ ) will rapidly grow to over $80 \%$ in a reasonable limited number of meetings (less than 5, see Figure 10).

The cost of the team work continues to grow with each meeting. The $\mathrm{X}$ axis in the graph of Figure 10 can be scaled with a cumulative team OPEX of 5 kEuro per meeting (using an integral OPEX with 250 Euro for salary $\&$ overhead per man hour, and a standardized 2 hours team meeting of 10 members). Regression is also possible, if the Cumulative POS declines, and results in shrinking EMV*. Clearly, it is economically attractive to invest time, resources and effort in building improved alignment in project teams.

\section{Conclusions and Recommendations}

Starting project teams off in a people-oriented approach, rather than goal-oriented increases their probability of success for an optimum project outcome. Checklist 1 provides a managerial checklist to promote the success of teams. If the quality of the social stability layers remains poor in the team only a percentage of the optimum project outcome can be realized. The method outlined here quantified how the loss in Net Present Value can be mitigated by a positive learning curve for any team (Figure 10). If team members manage to align in the three fundamental layers of team stability, their project outcome is optimized, as opposed to realizing only a fraction of the required project outcome.

As a generic rule, any team meeting needs a clear-cut agenda. Completion of the actions and decisions will make the further difference, and the quantification of Cornelis' Feelings Logic holds a powerful promise for tracking the progressive alignment of team members as they work to realize a common goal. The key to optimizing team performance lies locked in monitoring and influencing the degree of alignment between team members. Project teams should first work people-oriented on common core values and skills inventories (Checklist 1), before moving on toward a goal-oriented approach. An agenda always helps to start from a common expectation, a prerequisite for building alignment in teams. Avoid an outcome saying "Why was the meeting called?" Be careful with overemphasizing communication via modern ICT tools, as emotional signals are poorly captured and ICT may filter out important information from the message.

\section{Checklist 1: Managerial checklist for success of teams}

(1) Successful teams need a core of people that already hold shared values from the outset, and team leaders should act mostly people-oriented and then become more task-oriented only when the foundation of social stability layers has firmed up.

(2) In effective teams, the team members align on common culture values and build social bonding through mutual trust and acceptance.

(3) Teams benefit from consciously inventorying the skills needed for the task at hand and comparing these with the range of skills mastered and covered by team members. The emotional responses related to the skills layer of Cornelis are 'confidence' for those team members who have the appropriate skills - and 'frustration' for those that do not.

(4) An open dialogue about the team's strengths in skills and weaknesses in is itself an exercise that will help to build a stronger social Skills Layer for the team. Further strengthening of the skills layer is possible by dedicated training and by inviting experts for advice or by recruiting new team members.

(5) The three social stability layers of Cornelis 'stack' on top of one another. In other words, fulfilling the Skills Layer is contingent on fulfilling the Culture Layer. It is highly implausible for a member of a team to realize his or her goals and ambitions (self-actualization) if not supported by a social culture, common understanding of core values, and effective sharing of skills and knowledge. 
(6) Once the team aligns on core values and skills needed, the team can move on to define goals and work the task (Figure. 4). When a team has defined the goals aspired, working of the tasks by the team follows naturally. The team will work with maximum collaboration between members to tap their creativity, passion, spontaneity, feedback and productivity will be high.

(7) A team becomes happy and successful if the self-fulfilment layer can be realized by alignment of team members, and sad and unsuccessful if this is not the case. Effective goal setting for the team becomes possible only when the vision for the project's objectives is shared by all team members.

(8) The most fundamental emotional response is related to the self-actualization or self-fulfilment level or stability layer; 'self-actualization' refers to people's ability to formulate and realise their goals and ambitions within the social entity of a team.

The model outlined in this study is powerful and preliminary tested in survival game simulations. Given the positive impact of effective team learning on the Cumulative POS (Figure 10), monitoring team performance seems worthwhile. Table 2 can be used for monitoring and improving team alignment in any organization - and the payback can be attractive. Further benchmarking requires a client study to monitor team performance over an extended period. Applications are possible in all kinds of functional teams, including change management teams that need to build coalitions to effectuate lasting change. Value-adding by team excellence or better-than-expected project outcomes remain worthwhile alternatives to value-lost by underperformance in teams - truly competitive companies can no longer afford average team outcomes. Optimizing team outcomes are a means to enhance organizational competitiveness.

This study is not in disagreement with other team work models such as those that consider a degree of self-organization, preceded by divergent-thinking or even chaos according to complexity theory, highlighted in two recent books (Hazy et al., 2007; Uhl-Bien \& Marion, 2008). Starting out with a laissez-faire approach in team work as opposed to Venturi style management (e.g., Weijermars, 2008), does not necessarily mean that alignment of team members, and the associated convergence of ideas, is postponed. Loosening the managerial reins of goal-oriented functions and business operations can be an effective way to give teams room for self-organization into a focused sharing of knowledge and skills. Self-organization is known to be pre-eminent in the fertile region where novelty is created (Comfort, 1994). Effective top-down vision-sharing is still helpful for teams when this involves both the adoption of a shared vision and the delegation of leadership to teams to help realize the organizational vision and associated goals. But a goal-oriented approach where top-down control is too strong - an inherent danger in Venturi type or overly goal-oriented management - may make teams passive and dependent (Argyris, 1957). Keeping a proper balance between core business goals that remain proactively fuelled by innovation and new ideas remains important - modern management commonly knows how to utilize the benefits of Venturi style and Complexity Leadership philosophies. Ultimately, team alignment (i.e., building a high POS) is required to realize the team's project outcome; and this is not necessarily counter to creating new knowledge if the team optimizes skills and knowledge sharing for innovative solutions.

\section{Acknowledgements}

Dr. George DeVries Klein and Dr. Alfred Kjemperud provided helpful comments on the manuscript. This study was sponsored by Alboran Energy Strategy Consultants, which specializes in independent strategy analysis and training to support energy executives and professionals in strategy, leadership and change management.

\section{References}

Amabile, T. M. (1996). Creativity in Context. Westview Press, Boulder, Colorado.

Amabile, T. M. (1998). How to kill creativity. Harvard Business Review.

Argyris, C. (1957). Personality and Organization. Harper Collins, New York.

Axelrod, R. (1997). The Complexity of Cooperation. Princeton University Press, Princeton, New Jersey.

Baker, S. (2008). The Numerati. Houghton Mifflin Books. New York.

Belbin, M. (1993). Team Roles at Work. Butterworth Heinemann.

Blake, R., \& Mouton, J. (1964). The managerial grid: key orientations for achieving production through people. Houston, Texas, Gulf.

Collins, J. (2001). Good to Great: Why Some Companies Make the Leap... and Others Don't. Harper Collins Publishers Inc., New York. 
Comfort, L. K. (1994). Self-Organization in Complex Systems. Journal of Public Administration Research Theory, 4, 393-410.

Conner, D. (1992). Managing at the speed of change: How resilient managers succeed and prosper where others fail. New York, Villard.

Cornelis, A. (1988). Logica van het gevoel, filosofie van de stabiliteitslagen in de cultuur als nesteling der emoties. Uitgave Stichting Essence Amsterdam/Brussel/Middelburg, 9 ${ }^{\mathrm{e}}$ druk, 2000.

Drexler, A., Sibbet, D., \& Forrester, R. (1988). The team performance model. In W. B. Reddy, \& K. Jamieson (Eds.), Teambuilding: blueprints for productivity and satisfaction (pp. 45-61). Alexandria, VA: NTL Institute for the Applied Behavioral Sciences; San Diego, CA: University Associates.

Druskat, V. U., \& Wolff, S. B. (2001). Building the Emotional Intelligence of Groups. Harvard Business Review.

Fiedler, F. E. (1967). A Theory of Leadership Effectiveness. New York: McGraw-Hill

Fischer, B., \& Boynton, A. (2005). Virtusoso Temas. Harvard Business Review.

Goleman, D. (1996). Emotional Intelligence-Why it can Matter More Than IQ. Bloomsbury.

Goleman, D. (1997). Emotional Intelligence. Bantam Books, New York.

Goleman, D. (2000). Working with Emotional Intelligence. Bantam Books, New York.

Gratton, L., \& Erickson, T. J. (2007). Eight ways to build collaborative teams. Harvard Business Review.

Hazy, K., Goldstein, J., \& Lichtenstein, B. (2007). Complex Systems Leadership Theory. ISCE Publishers, Mansfield, MA.

Herrmann, N. (1996). The whole brain business book. New York: Mc Graw Hill .

Hoegl, M., \& Parboteeah, K. P. (2007). Creativity in innovative projects: how teamwork matters. Journal of Engineering and Technology Management, 24, 148-166.

Hofstede, G., \& Hofstede, G. J. (2004). Cultures and Organizations: Software of the Mind. McGraw-Hill, New York.

Johnston, D., \& Johnston, D. (2002). Economic Modeling and Risk Analysis Handbook. CEPMLP at the University of Dundee.

Johnston, D. (2003). International Petroleum Economics, Risk, and Contract Analysis. Penwell Books, USA.

Kirkpatrick, S. A., \& Locke, E. A. (1991). Leadership: Do traits matter?. Academy of Management Executive, 5 , 48-60.

Kjemperud, S. A. (2004). Risk analysis and petroleum economics, The Bridge Group, 4th Workshop of Cambodia PPM Case Study, Pnom Penn. Retrieved from http://www.ccop.or.th/ppm/

Klein, G. D. (1999). Navigating through an International Enhanced Oil Recovery Project: A Cross-Cultural Odyssey. The Professional Geologist, 36(7), 4-7.

Kotter, J. P. (1978). Organizational Dynamics: Diagnosis and Intervention. Addison-Wesley. New York.

Kotter, J. P., \& Rathgeber, H. (2006). Our Iceberg Is Melting: Changing and Succeeding Under Any Conditions. Macmillan, New York.

Lord, D., Etheridge, M. A., Willson, M., Hall, G., \& Uttley, P. J. (2001). Measuring exploration success: an alternative to the discovery-cost-per-ounce method of quantifying exploration success. SEG Newsletter, 45, $10-16$.

Lumsdaine, E. M., Lumsdaine, \& Shelnutt, J. W. (1999). Creative Problem Solving and Engineering Design. McGraw-Hill, New York, NY.

Oliver, P., Kreuzer, O. P., Etheridge. M. A., Guj, P., McMahon, M. E., \& Holden, D. J. (2008). Linking Mineral Deposit Models to Quantitative Risk Analysis and Decision-Making in Exploration. Economic Geology, 103(4), 829-850. http://dx.doi.org/10.2113/gsecongeo.103.4.829

PROSCI. (2007). PROSCI best practices in change management 2007 report. Prosci, Colorado.

Rhoads, G. (2005). Managing the Probability of Making at Least One Discovery. Gulf of Mexico Shelf Business Unit Chevron, Conference Presentation June 2005. 
Ridley, M. (1998). The Origins of Virtue: Human Instincts and the Evolution of Cooperation. New York: Viking.

Thompson, L. (2003). Improving the creativity of organizational work groups. Academy of Management Executive, 17(1), 96-109. http://dx.doi.org/10.5465/AME.2003.9474814

Trompenaars, F., \& Hampden-Turner, C. (1997). Riding the Waves of Culture. Nicholas Brealey Publishing, Londen.

Tuckman, B. W. (1965). Developmental sequence in small groups. Psychological Bulletin, 63, 384-399. http://dx.doi.org/10.1037/h0022100

Uhl-Bien, M., \& Marion, R. (2008). Complexity \& Leadership (Vol. I). Information Publishing Associates, USA.

Welsh, M. B., Begg, S. H., \& Bratvold, R. B. (2008). Modeling the Economic Effects of Cognitive Biases in Oil and Gas Decisions. Journal of Petroleum Technology, 659-661.

Weijermars, R. (2008). Balancing Venturi and Laissez-Faire Management Styles: Insights from Fluid Mechanical Analogs. Journal of Systemics, Cybernetics and Informatics, 5(6), 1-10.

Weijermars, R. (2011). Building Corporate IQ: Moving the Energy Business from Smart to Genius: Executive Guide to preventing Costly Crises. Springer, London.

Weijermars, R., \& De Jong, V. (2008). Closing Communication Gaps can improve the Success of Oil \& Gas Ventures. Oil and Gas Business Journal, 1-24.

Weijermars, R., De Jong, V., \& Van der Kooi, K. (2008). Cultural challenges in oil and gas industry management. World Oil, 229(4), 223-228.

Willigers, B. J. A., \& Majou, F. (2010). Creating efficient portfolios that match competing corporate strategies. SPE Paper 129259. 